JPSCR: Journal of Pharmaceutical Science and Clinical Research, 2020, 02, 179-188

DOI: $10.20961 /$ jpscr.v5i2.41929

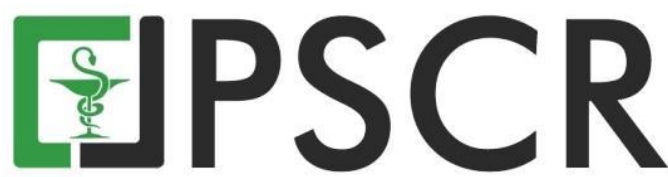

\title{
Identifikasi Parasetamol dan Asam Mefenamat pada Jamu Pegel Linu dan Asam Urat yang Beredar di Daerah Istimewa Yogyakarta
}

\author{
Sabtanti Harimurti*, Syaripah Ulandari, Hari Widada dan Vella Lailly Damarwati \\ Program Studi Farmasi, Fakultas Kedokteran dan Ilmu Kesehatan, Universitas Muhammadiyah Yogyakarta, Jl. \\ Brawijaya, Tamantirto, Kasihan, Bantul, Yogyakarta, Indonesia, 55183 \\ *email korespondensi: sabtanti@umy.ac.id \\ Received 04 June 2020, Accepted 04 October 2020, Published 30 October 2020
}

\begin{abstract}
Abstrak: Jamu merupakan obat tradisional yang banyak digunakan masyarakat untuk mencegah atau membantu menyembuhkan berbagai penyakit. Peningkatan minat masyarakat untuk mengkonsumsi jamu sering disalahgunakan oleh produsen dengan menambahkan Bahan Kimia Obat (BKO) untuk mendapatkan omzet yang lebih karena diyakini akan lebih cepat memberikan efek. Pencampuran BKO pada jamu dilarang oleh pemerintah Indonesia. Tingginya penggunaan jamu pegel linu dan asam urat di masyarakat luas, menginspirasi untuk melakukan identifikasi pencampuran $\mathrm{BKO}$ yang mempunyai efek sebagai penghilang rasa sakit seperti parasetamol dan asam mefenamat dalam jamu pegel linu dan jamu asam urat yang beredar di Daerah Istimewa Yogyakarta. Sehingga, tujuan dari penelitian ini yaitu mengidentifikasi pengunaan BKO pada jamu yang beredar di Yogyakarta. Metode analisis pada penelitian ini menggunakan KLT-Densitometri. KLT digunakan untuk analisis kualitatif. Pada pengujian menggunakan KLT, fase diam yang digunakan adalah silika GF254 dan fase gerak klorofrom-etanol dengan perbandingan 8:1. Identifikasi bercak menggunakan sinar UV pada panjang gelombang $254 \mathrm{~nm}$. Kemudian untuk analisis kuantitatif digunakan densitometri. Berdasarkan hasil analisis KLT menunjukkan bahwa terdapat tiga sampel jamu yang mengandung parasetamol dari 14 sampel yang dikumpulkan dan tidak ada yang mengandung asam mefenamat. Sampel jamu yang mengandung parasetamol adalah sampel nomor 3, 7, dan 10. Ketiga sampel tersebut mengandung parasetamol $0,04 \%(\mathrm{~b} / \mathrm{v}), 0,30 \%(\mathrm{~b} / \mathrm{v})$, dan $0,13 \%$ (b/v), secara berurutan.
\end{abstract}

Kata kunci: Jamu; Parasetamol; Asam mefenamat; KLT-Densitometri; BKO

Abstract. Identification of Paracetamol and Mefenamic Acid in Jamu Pegel Linu and Uric Acid Circulating in Special Region of Yogyakarta. Jamu is a traditional medicine that is widely used by people to prevent or help cure various diseases. Increased public interest in consuming herbal medicine is often abused by producers by adding medicinal chemicals (BKO) to get more turnover because it is believed to have an effect. The mixing of BKO in herbal medicine is prohibited by the Indonesian government. The high use of jamu pegel linu and uric acid in the wider community inspired to identify the mixing of BKO, which has an effect as pain relievers such as paracetamol and mefenamic acid in jamu pegel linu and jamu asam urat, which are circulating in the Special Region of Yogyakarta. Therefore, this study aimed to identify the use of BKO in herbal medicine in Yogyakarta. The method of analysis in this study used TLC-Densitometry. TLC was used for qualitative analysis. In the TLC test, the stationary phase used was silica GF254, and the mobile phase was chloroform-ethanol with a ratio of 8: 1. Spot identification was using UV light at a wavelength of $254 \mathrm{~nm}$. Then for quantitative analysis, used densitometry. Based on the results of TLC analysis showed that there were three 
samples of jamu containing paracetamol from 14 samples collected and none containing mefenamic acid. The jamu samples containing paracetamol were sample number 3, 7, and 10 . The three samples contained paracetamol $0.04 \%(\mathrm{w} / \mathrm{v}), 0.30 \%(\mathrm{w} / \mathrm{v})$, and $0.13 \%(\mathrm{w} / \mathrm{v})$, respectively.

Keywords: Jamu; Paracetamol; Mefenamic acid; TLC-densitometry; adulteration

\section{Pendahuluan}

Obat tradisional atau sering disebut sebagai jamu merupakan bahan atau ramuan bahan yang berasal dari tumbuhan, hewan, mineral, sediaan sarian (galenik) atau campuran bahanbahan tersebut yang secara turun menurun sudah digunakan untuk pengobatan dan dapat diterapkan sesuai dengan norma masyarakat yang berlaku (Menkes RI, 2012).

Menurut hasil Riset Kesehatan Dasar (Riskesdas) pada tahun 2018, sekitar 3,5\% penduduk Daerah Istimewa Yogyakarta dilaporkan mempunyai penyakit sendi. Sementara itu sekitar $48 \%$ penduduk Indonesia menggunakan jamu kemasan untuk menjaga kesehatan maupun untuk pengobatan (Kemenkes RI, 2018). Jenis jamu yang sering dicari di kalangan masyarakat baik oleh laki-laki maupun perempuan dewasa adalah jamu pegel linu dan asam urat (Riyanti et al, 2013). Penelitian berikut menunjukkan bahwa beberapa jamu pegel linu dan asam urat mengandung BKO yang mempunyai efek sebagai antiradang dan penghilang rasa sakit. Parasetamol dilaporkan dicampurkan dengan jamu pegel linu yang diperoleh dari kawasan industri kecamatan Kibin kabupaten Serang (Indriatmoko et al, 2019). Rollando dan kawan-kawan melaporkan bahwa dari 30 jamu pegel linu yang beredar di kota Malang megnandung fenilbutazon (Rollando et al, 2019). Dilaporkan oleh Rahmatullah et al (2018), bahwa beberapa jamu asam urat yang beredar di Kabupaten Pekalongan mengandung piroksikam dan allopurinol (Rahmatullah et al, 2018). Wirastuti et al (2016) juga mengidentifikasi BKO prednison obat anti radang ditambahkan pada jamu rematik. Jamu pegel linu yang beredar di Pekalongan juga dilaporkan mengandung asam mefenamat (Rusmalina et $a l, 2020)$. Berdasarkan beberapa hasil penelitian bisa dilihat bahwa beragam obat antiradang dan penghilang rasa sakit sering disalahgunakan untuk meningkatkan efek dari jamu pegel linu dan asam urat sehingga dapat menguntungkan perusahaan jamu tertentu. Laporan BPOM menyatakan bahwa BKO yang sering dicampurkan pada jamu adalah parasetamol (BPOM RI, 2017).

Pada dasarnya penggunaan BKO pada jamu akan berakibat buruk bagi kesehatan. Efek jamu biasanya tidak instan, oleh karena itu biasanya dalam mengkonsumsi jamu perlu waktu yang cukup lama dan rutin. Sementara itu apabila pada jamu yang ditambahkan BKO tentunya akan memberikan efek yang cepat, dan ini akan memberikan kepercayaan pada masyarkat akan kasiatnya. Namun dibalik itu, penggunanan BKO untuk pengobatan harus dengan pengawasan 
yang ketat karena efek samping yang munkin ditimbulkan (Roberts et al, 2015). Sebagai contoh, penggunaan parasetamol secara overdosis atau tidak sesuai dengan pemakaian akan menyebabkan terbentuknya metabolit toksik, yaitu $N$-acetyl-p-benzoquinoneimine (NAPQI) yang dapat berefek merusak hati (Twycross et al, 2013). Kemungkinan timbulnya metoblit toksik pada penggunaan parasetamol juga dilaporkan olah peneliti berikut. Penelitian laboratorium yang dilakukan oleh Widagdo et al (2016) menyebutkan bahwa pemberian parasetamol pada sel usus yang bersamaan dengan kurkumin dalam jangka waktu yang lama akan memberikan toksisitas terhadap sel. Hal ini disebabkan karena kurkumin akan menginhibisi enzim pemetabolisme parasetamol yang akhirnya berakibat pada peningkatan jumlah metabolit parasetamol yang toksis terhadap sel (Widagdo et al, 2016). Melihat hasil penelitan yang dilakukan oleh Widagdo et al (2016), dimungkinkan penggunakan parasetamol yang diberikan bersamaan dengan kurkumin akan membawa akibat yang tidak baik, mengingat bahan dasar jamu sering mengandung kurkumin.

Mengingat masyarakat Indonesia sering mengkonsumsi jamu dan sekitar 3,5\% masyarakat Yogyakarta menderita penyakit sendi, serta berdasarkan hasil penelitian tentang bahaya pencampuran BKO pada jamu dan banyaknya temuan pencampuran BKO pada jamu pegel linu dan asam urat, maka penelitian tentang identifikasi pencampuran BKO parasetamol dan asam mefenamat pada jamu asam urat dan pegel linu yang beredar di Daerah Istimewa Yogyakarta perlu dilakukan. Sampel diambil dari pedagang jamu kemasan di Daerah Istimewa Yogyakarta karena belum ada penelitian yang melaporkan pencampuran BKO parasetamol dan asam mefenamat pada jamu pegel linu dan asam urat di daerah ini. Sehingga, tujuan dari penelitian ini yaitu mengidentifikasi pengunaan BKO pada jamu yang beredar di Yogyakarta. Metode yang dipilih pada penelitian ini adalah KLT-densitometri. Metode ini dipilih karena metode ini sedeharna, cepat dan murah dalam pengaplikasiannya (Uchadadiya et al, 2013; ElHoussini, 2013; Abdelwahab et al, 2019). Beberapa publikasi yang telah dilakukan oleh para peneliti untuk pemakaian metode KLT-densitometri dalam identifikasi parasetamol dan asam mefenamat antara lain sebagai berikut. Riyanti et al (2013) dan Saputra (2017) telah mengidentifikasi parasetamol dalam jamu pegel linu yang beredar di kota Cimahi (Jawa Barat) dan Kota Bandar (Kediri, Jawa Timur). Metode KLT-densitometri juga sudah diusulkan untuk quality control rutin dalam produksi tablet parasetamol yang dicampur dengan bahan-bahan lain. Validasi metode ini dilaporkan sangat baik memenuhi standar yang ditetapkan oleh beberapa guideline. Pyka dan timnya (2013) melaporkan bahwa metode KLT-densitometri bisa menggantikan metode yang tertuang dalam farmakope yaitu metode spektofometri-UV dalam identifikasi dan penetapan kadar parasetamol dalam tablet (Pyka et al, 2013). Sementara itu, 
identifikasi asam mefenamat juga dilaporkan oleh beberapa peneliti menggunanakan KLTdensitometri. Peneliti-peneliti tersebut antara lain adalah sebagai berikut. Rusnaeni dan kawankawan menggunakan KLT untuk mengidentifikasi asam mefenamat ada jamu rematik yang beredar di kota Heram Jayapura (Rusnaeni et al, 2016). Kemudian Rusmalina dan kawankawan menggunakan KLT-densitometri untuk mengidentifikasi asam mefenamat pada jamu pegel linu di kabupaten Pekalongan (Rusmalina et al, 2020). Bahkan, Hayun dan Karina melakukan validasi KLT-densitometri secara simultan untuk sampel mengandung asam mefenamat dan obat-obat penghilang rasa sakit lainnya (Hayun dan Karina, 2016). Berdasarkan dari beberapa peneliti yang menggunakan KLT-densitometri untuk identifikasi parasetamol dan asam mefenamat pada sediaan jamu pegel linu, asam urat dan rematik, maka metode KLTdensitometri dipilih untuk penelitian ini.

\section{Bahan dan Metode}

\subsection{Bahan}

Sampel jamu pegel linu dan asam urat diperoleh dari para pedagang jamu yang berjualan di Daerah Istimewa Yogyakarta pada bulan Maret 2019. Lempeng KLT Silika gel GF 254 yang digunakan adalah dari Merck (Germany) dan pembanding/standar menggunakan tablet $500 \mathrm{mg}$ parasetamol dan $500 \mathrm{mg}$ asam mefenamat yang diproduksi oleh Novapharin Pharmaceutical Indonesia. Untuk solven yang digunakan untuk elusidasi adalah klorofrom p.a dan etanol p.a yang diperoleh dari Merck (Germany).

\subsection{Metode}

\subsubsection{Pembuatan larutan kurva baku parasetamol}

Satu (1) tablet $500 \mathrm{mg}$ parasetamol dan satu (1) tablet $500 \mathrm{mg}$ asam mefenamat masingmasing ditimbang secara seksama dengan menggunakan timbangan analitik (Mettler Tolledo®) kemudian digerus terpisah. Selanjutnya masing-masing ditimbang secara seksama seberat $1 / 5$ berat tablet untuk menyiapkan parasetamol dan asam mefenamat setara dengan $100 \mathrm{mg}$. Serbuk kemudian dilarutkan menggunakan etanol p.a dalam sebuah beaker glass (Pyrex $\left.{ }^{\circledR}\right)$ yang terpisah kemudian disaring. Selanjutnya masing-masing dimasukkan dalam labu ukur $10 \mathrm{~mL}$ (Pyrex®) dan ditambahkan etanol p.a sampai 10 mL. Stok-stok larutan ini kemudian digunakan untuk standar pada identifikasi awal parasetamol dan asam mefenamat menggunakan KLT pada sampel jamu. Lebih lanjut untuk penetapakan kadar, stok-stok larutan ini digunakan untuk membuat seri kadar BKO dengan konsentrasi sekitar 0,5\% (b/v); 0,25\% (b/v); 0,125\% (b/v); dan $0,0625 \%(\mathrm{~b} / \mathrm{v})$. 


\subsubsection{Pembuatan larutan sampel}

Sampel (jamu) ditimbang secara seksama masing-masing seberat $116 \mathrm{mg}$ (setra dengan berat serbuk parasetamol yang digunakan untuk membuat kurva baku) menggunakan timbangan analitik (Mettler Tolledo®). Selanjutnya sampel dilarutkan dengan etanol p.a dalam beaker glass $\left(\right.$ Pyrex $\left.{ }^{\circledR}\right)$ kemudian disaring. Kemudian ditambahkan etanol p.a sampai $10 \mathrm{~mL}$ dalam sebuah labu ukur $10 \mathrm{~mL}$ (Pyrex $\left.{ }^{\circledR}\right)$ dan siap untuk dilakukan analisis.

\subsubsection{Analisis kualitatif dan analisis kuantitatif}

Analisis kualitatif dilakukan dengan menggunakan lempeng KLT silika gel GF 254 (Merck). Plat dipotong dengan ukuran $10 \mathrm{~cm}$ x $10 \mathrm{~cm}$ kemudian diaktifkan dengan memanaskannya di atas hot plate untuk beberapa lama ( \pm 10 menit). Selanjutnya larutan sampel yang sudah disiapkan ditotolkan pada plat KLT dengan menggunakan micro syringe (Hamilton ${ }^{\circledR}$ ) sebanyak $50 \mu$ l. Jarak antar totolan adalah $1 \mathrm{~cm}$ dan elusi ditargetkan setinggi 7 $\mathrm{cm}$. Sembari menyiapkan sampel, chamber KLT (Camag®) dijenuhkan dengan menggunakan fase gerak klorofrom-etanol (8:1) (Hayun \& Karina, 2016) dan selanjutnya dilakukan elusi sampel ketika chamber telah jenuh. Interpretasi adanya parasetamol dan asam mefenamat dalam sampel dilakukan dengan membandingkan bercak standar parasetomol dan asam mefenamat dengan bercak yang ada pada sampel. Pembandingan dilakukan dengan melihat bercak di bawah lampu UV pada panjang gelombang $254 \mathrm{~nm}$. Kemudian untuk analisis kuantitatif, lempeng KLT dimasukkan dalam alat densimometri (Camag TLC Scanner 4) untuk dibaca luas area yang ditimbulkan oleh bercak yang mirip nilai Rf dengan bercak parasetamol dan asam mefenamat standard. Luas area yang diperoleh digunakan untuk menghitung kadar parasetomol yang terdapat dalam jamu. Perhitungan didasarkan pada kurva baku yang telah dibuat sebelumnya.

\section{Hasil dan Pembahasan}

Pada saat ini terjadi peningkatan trend untuk kembali menggunakan bahan alam atau herbal untuk pengobatan dibanding obat sintetik (Calahan et al, 2016; Yamin \& Burhanudin, 2018; Andriati dan Wahjudi, 2016). Trend ini dimanfaatkan oleh pihak tidak bertanggung jawab yang memproduksi obat tradisonal untuk mengeruk keuntungan, yaitu dengan menambahkan BKO untuk mempercepat aksi sehingga pengguna akan banyak membeli. Salah satu BKO yang sering ditemukan ditambahkan adalah parasetamol (BPOM RI, 2017). Selain itu asam mefenamat juga ditemukan pada jamu pegel linu yang berdar di kabupaten Pekalongan (Rusmalina et al, 2020).

Pada penelitian ini, analisis dilakukan menggunakan metode KLT-densitometri. dengan fase diam silika gel GF 254 dan fase gerak campuran kloroform-etanol (8:1). Pemilihan fase 
diam silika gel GF 254 adalah untuk memudahkan identifikasi, dimana pada penyinaran dengan lampu UV $254 \mathrm{~nm}$ fase diam akan berfluoresen sedangkan bercak parasetamol akan meredam sehingga bercak akan jelas terlihat. Peredaman fluoresensi fase diam karena parasetamol dan asam mefenamat dikarenakan kedua zat tersebut mempunyai gugus kromofor dan auksokrom yang mampu menyerap sinar UV (Tulandi, 2015; Musiam \& Alfian, 2017; Rosalina, 2018).
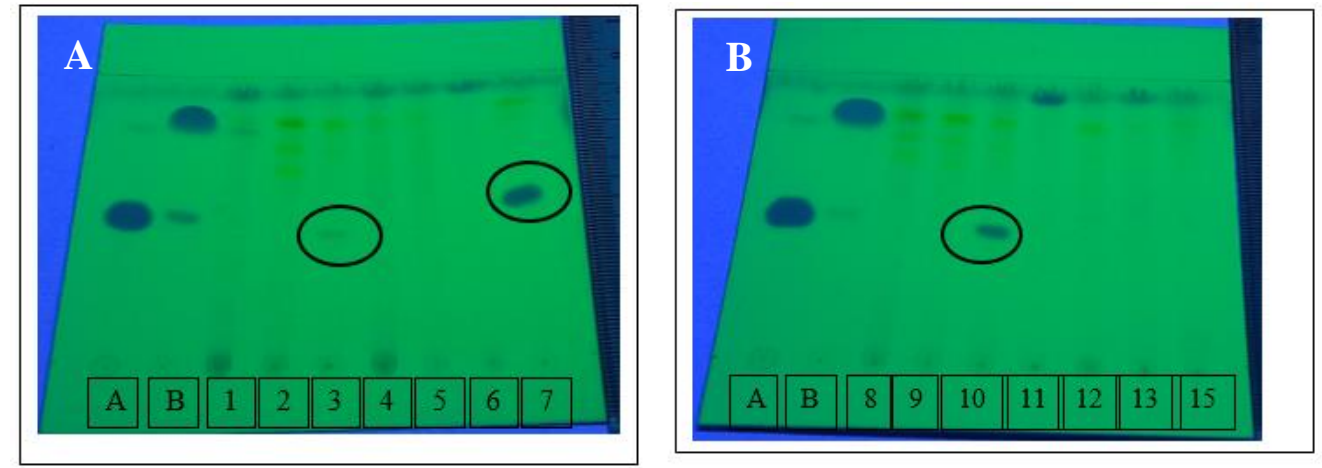

Gambar 1. Hasil KLT (A) sampel 1-7; (B) sampel 8-14. Pada gambar (a): A: baku parasetamol, B: baku asam mefenamat, 1: sampel ES, 2: sampel PO, 3: sampel SM, 4: sampel PS, 5: sampel PA, 6: sampel KB dan 7: sampel AS. Pada gambar (b): A: baku parasetamol. B: baku asam mefenamat, 8: sampel UI, 9: sampel AT, 10: sampel JE, 11: sampel CM, 12: sampel PL, 13: sampel PJ dan 14: sampel KT.

Berdasarkan uji KLT, sampel jamu yang terbukti mengandung parasetamol kemudian dilanjutkan uji kuantitatif mengguankan densisometri (Gandjar \& Abdul Rohman, 2007). Kurva baku yang dibuat bisa diliat pada Gambar 2. Sementara Hasil analisis semua sampel jamu no 1 -14 bisa dilihat pada Tabel 1 dan kromatogram setiap sampel jamu bisa dilihat pada Gambar 3.

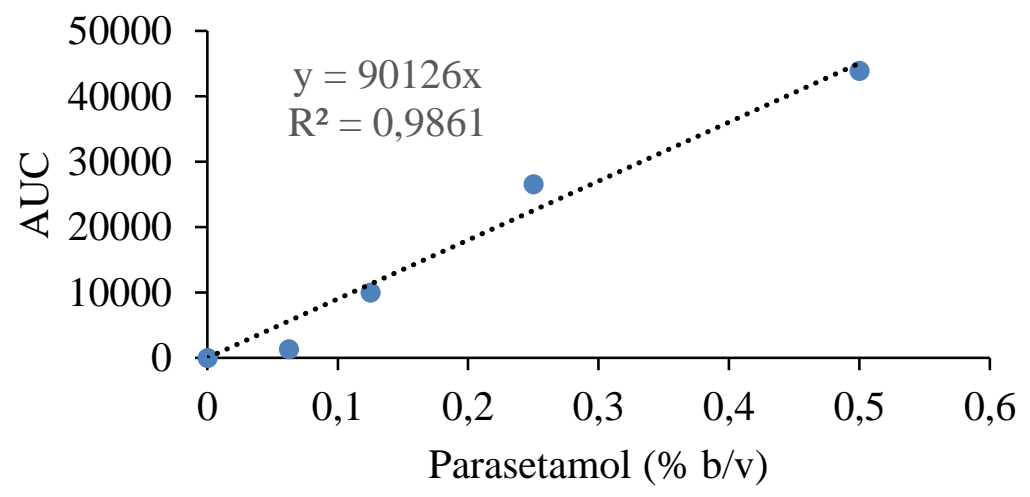

Gambar 2. Kurva baku hubungan kadar parasetamol dan AUC dari analisis Densitometer.

Sementara itu fase gerak yang dipilih berdasarkan prinsip KLT like dissolve like. Parasetamol dan asam mefenamat merupakan senyawa semipolar sehingga bisa dielusi menggunakan fase gerak yang semi polar (Depkes RI, 1995). Dari Gambar 1 (A) dan (B) bisa 
dilihat bahwa sampel no 3, 7 dan 10 terdapat bercak yang mempunyai warna dan Rf serupa dengan standar parasetamol yang digunakan. Pada sampel 1, 2, 8 dan 9 memiliki bercak yang mempunyai Rf mirip dengan bercak asam mefenamat, tetapi warna bercak berbeda dengan warna bercak asam mefenamat, yaitu memiliki warna kekuningan. Bisa dikatakan bahwa sistem KLT yang digunakan tidak spesifik untuk sampel yang diteliti karena tidak bisa membedakan asam mefenamat dan senyawa berwarna kekuningan, sehingga perlu dilakukan pemilihan sistem KLT yang sesuai pada penelitian selanjutnya. Oleh karena itu pada penelitian ini disimpulkan bahwa sampel jamu yang dianalisis mengandung BKO parasetamol pada sampel no 3, 7, dan 10 dan tidak ada sampel yang menganbdung BKO asam mefenamat. Standar parasetamol dan asam mefenamat yang digunakan pada penelitian ini adalah tablet parasetamol dan tablet asam mefenamat yang diperoleh dari Apotek yang bisa dipastikan kebenarannya.

Tabel 1. Hasil pemeriksaan kualitatif dan kuantitatif kandungan parasetamol dan asam mefenamat pada sampel jamu asam urat dan pegel linu yang beredar di Daerah Istimewa Yogyakarta.

\begin{tabular}{ccccc}
\hline $\begin{array}{c}\text { Nomer sampel } \\
(\text { Inisial })\end{array}$ & $\begin{array}{c}\text { Uji } \\
\text { kualitatif }\end{array}$ & Rf & AUC & Parasetamol (\% b/v) \\
\hline A & $\begin{array}{c}\text { Standard } \\
\text { Standard }\end{array}$ & $0,45 \pm 0,02$ & & \\
B & - & & & \\
$1(\mathrm{ES})$ & - & & & - \\
$2(\mathrm{PO})$ & + & $0,43 \pm 0,02$ & $3487,40 \pm 100$ & - \\
$3(\mathrm{SM})$ & - & & & $0,04 \pm 0,001$ \\
$4(\mathrm{PS})$ & - & & & - \\
$5(\mathrm{PA})$ & - & & & - \\
$6(\mathrm{~KB})$ & + & $0,49 \pm 0,02$ & $27156,60 \pm 421$ & $0,30 \pm 0,005$ \\
$7(\mathrm{AS})$ & - & & & - \\
$8(\mathrm{UI})$ & - & & & - \\
$9(\mathrm{AT})$ & + & $0,45 \pm 0,02$ & $11572,50 \pm 150$ & $0,13 \pm 0,0008$ \\
$10(\mathrm{JE})$ & - & & & - \\
$11(\mathrm{CM})$ & - & & & - \\
$12(\mathrm{PL})$ & - & & & - \\
$13(\mathrm{PJ})$ & - & & & \\
$14(\mathrm{KT})$ & & & & \\
\hline
\end{tabular}

Berdasarkan AUC yang diperoleh dari analisis menggunakan densitometer dan menggunakan kurva baku yang sudah disiapkan, maka konsentrasi parasetamol pada sampel no 3, 7 dan 10 adalah sebagai berikut $0,04 \%$ (b/v), 0,3\% (b/v), dan $0,13 \%(b / v)$. Hasil yang diperoleh dari penelitian ini sejalan dengan peneiltian sebelumnya bahwa paracetamol ditemukan dalam jamu pegel linu yang beredar di kota Cimahi (Jawa Barat) dan kota Bandar (Jawa Timur) (Riyanti et al, 2013; Saputra, 2017). Kemungkinan sampel yang diteliti adalah sama, tetapi dengan hasil penelitian ini bisa diasumsikan bahwa penyebaran jamu pegel linu dan jamu asam urat yang mengandung BKO menyebar di banyak daerah. Hal ini adalah 
masalah yang perlu diperhatikan oleh masyarakat luas agar lebih berhati-hati dalam mengkonsumsi jamu.
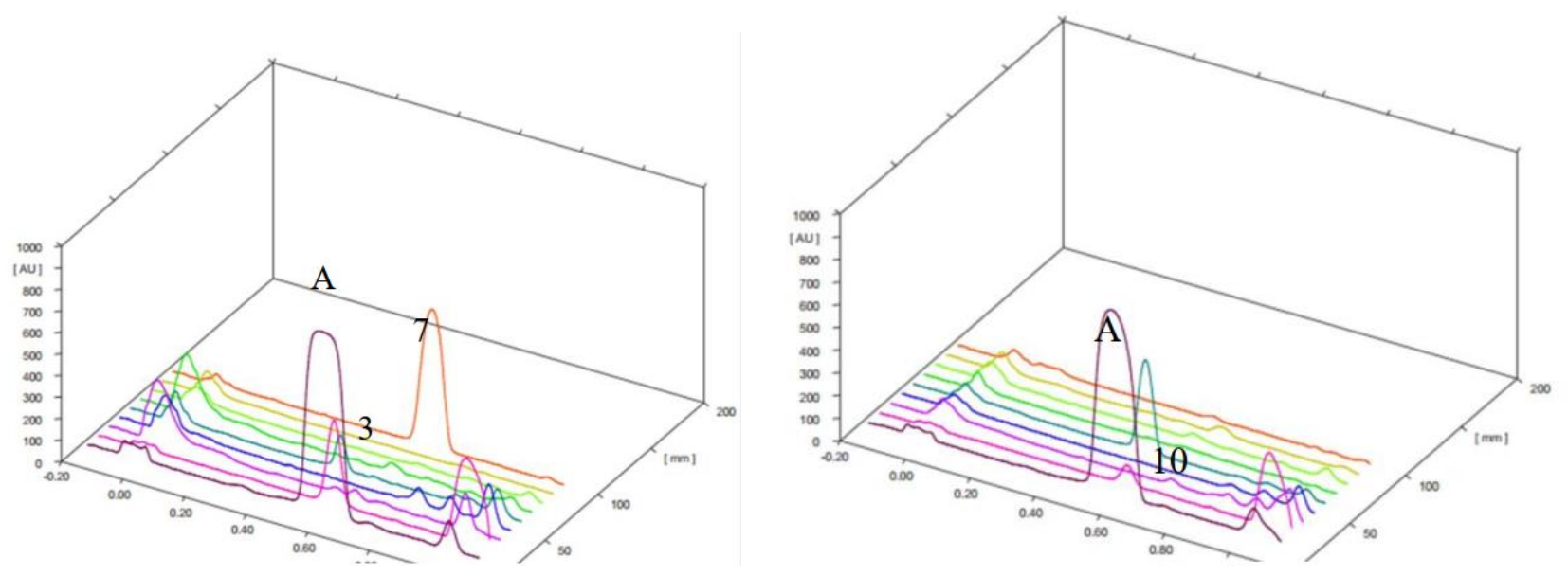

Gambar 3. Kromatogram analisis densitometer standar parasetamol dan sampel jamu nomer 1 - 7. Keterangan: (A) baku parasetamol; (3) sampel inisial SM, (7) sampel dengan inisial AS dan (10) sampel dengan inisial JE.

\section{Kesimpulan}

Berdasarkan hasil penelitian yang telah dilakukan pada 14 jamu pegel linu dan asam urat yang beredar di Daerah Istimewa Yogyakarta didapatkan bahwa sampel nomer 3 (SM), 7 (AS) dan 10 (JE) terbukti mengandung BKO parasetamol dengan kadar pada masing-masing sampel sebesar $0,04 \%$ (b/v), 0,30\% (b/v), dan $0,13 \%(b / v)$.

\section{Ucapan Terimakasih}

Ucapan terimakasih yang setinggi-tingginya kepada Universitas Muhammadiyah Yogyakarta yang telah memberikan dana dan fasilitas dalam pelaksanaan penelitian ini.

\section{Deklarasi Konflik Kepentingan}

Semua penulis menyatakan tidak ada konflik kepentingan terhadap naskah ini.

\section{Daftar Pustaka}

Abdelwahab, N. S., Abdelaleem, E. A., \& Abdelrahman, M. M. (2019). HPTLC-densitometric method for determination of ascorbic acid, paracetamol and guaifenesin in presence of their toxic impurities. Journal of chromatographic science, 57(2): pp. 149-155.

Andriati, A. dan Wahjudi, R. T. (2016). Tingkat penerimaan penggunaan jamu sebagai alternatif penggunaan obat modern pada masyarakat ekonomi rendah-menengah dan atas. Masyarakat, Kebudayaan dan Politik, 29(3): pp.133-145.

BPOM RI. (2017) Obat Tradisional yang Mengandung Bahan Kimia Obat. Jakarta: public warning . 
Calahan, J., Howard, D., Almalki, A. J., Gupta, M. P., \& Calderón, A. I. (2016). Chemical adulterants in herbal medicinal products: a review. Planta Med, 82(6): pp. 505-515.

Depkes, R. I. (1995). Farmakope Indonesia edisi IV. Jakarta: Departemen Kesehatan Republik Indonesia, 45.

El-Houssini, O. M. (2013). Rp-LC and TLC Densitometric Determination of paracetamol and pamabrom in presence of Hazardous Impurity of paracetamol and Application to pharmaceuticals. Analytical chemistry insights, 8, ACI-S12349.

Gandjar, I. G., \& Rohman, A. (2007). Kimia Farmasi Analisis. Pustaka Pelajar. Yogyakarta

Hayun, H., \& Karina, M. A. (2016). Pengembangan dan Validasi Metode KLT-Densitometri untuk Analisis secara simultan Parasetamol, Asam Mefenamat dan Ibuprofen dalam Jamu "Pegel Linu". Jurnal Sains Farmasi \& Klinis, 2(2): 150-161.

Indriatmoko, D. D., Rudiana, T., \& Saefullah, A. (2019). Analisis Kandungan Parasetamol Pada Jamu Pegal Linu Yang Diperoleh Dari Kawasan Industri Kecamatan Kibin Kabupaten Serang. Jurnal Itekima, 33.

Kemenkes, R. I. (2018). Laporan Nasional Riskesdas 2018. Jakarta: Kemenkes RI, 154-66.

Menkes, R. I. (2012). Peraturan Menteri Kesehatan Republik Indonesia No. 007 Tahun 2012 Tentang Registrasi Obat Tradisional.

Musiam, S., \& Alfian, R. (2017). Validasi Metode Spektrofotometri Uv Pada Analisis Penetapan Kadar Asam Mefenamat Dalam Sediaan Tablet Generik. Jurnal Ilmiah Ibnu Sina, 2(1): pp. 31 - 43.

Pyka, A., Budzisz, M., \& Dołowy, M. (2013). Validation thin layer chromatography for the determination of acetaminophen in tablets and comparison with a pharmacopeial method. BioMed research international.

Rahmatullah, S., Slamet, S., \& Fikri, A. (2018). Analisis Kualitatif Kandungan Bahan Kimia Obat (BKO) Dalam Jamu Asam Urat yang Beredar di Kabupaten Pekalongan. Proceeding of the URECOL, 566-575.

Riyanti, S., Sutardi, O. I., \& Ratnawati, J. (2013). PEMANTAUAN KUALITAS JAMU PEGAL LINU YANG BEREDAR DI KOTA CIMAHI. Kartika: Jurnal Ilmiah Farmasi, 1(1): pp. 45-48.

Roberts, E., Nunes, V. D., Buckner, S., Latchem, S., Constanti, M., Miller, P., Doherty, M., Zhang, W., Birrell, F., Porheret, M., and Dziedzic, K. (2016). Paracetamol: not as safe as we thought? A systematic literature review of observational studies. Annals of the rheumatic diseases, 75(3): pp. 552-559.

Rollando, R., Embang, E. D., \& Monica, E. (2019). Penetapan Kadar Fenilbutazon Dan Parasetamol Didalam Jamu Pegal Linu Yang Beredar Di Kota Malang Secara Kromatografi Lapis Tipis Densitometri. Jurnal Insan Farmasi Indonesia, 2(1): pp. 126138.

Rosalina, V. (2018). Analisis Kadar Sedian Parasetamol Syrup Pada Anak Terhadap Lama Penyimpanan Dan Suhu Penyimpanan. WARTA BHAKTI HUSADA MULIA, 5(1).

Rusmalina, S., Khasanah, K., \& Nugroho, D. K. (2020). Deteksi Asam Mefenamat pada Jamu Pegel Linu yang beredar di Wilayah Pekalongan. Pharmacon: Jurnal Farmasi Indonesia, pp. 51-60.

Rusnaeni, R., Sinaga, D. I., Lanuru, F., Payungallo, I. M., \& Ulfiani, I. I. (2016). Identifikasi Asam Mefenamat Dalam Jamu Rematik Yang Beredar Di Distrik Heram Kota Jayapura, Papua. PHARMACY: Jurnal Farmasi Indonesia (Pharmaceutical Journal of Indonesia), 13(1): pp. 84-91.

Saputra, S. A. (2017). Identifikasi Bahan Kimia Obat Dalam Jamu Pegel Linu Seduh Dan Kemasan Yang Dijual Di Pasar Bandar. Jurnal Wiyata: Penelitian Sains dan Kesehatan, 2(2): pp. 188-192.

Tulandi, G. P. (2015). Validasi Metode Analisis untuk Penetapan Kadar Parasetamol dalam Sediaan Tablet Secara Spektrofotometri Ultraviolet. PHARMACON, 4(4). 
Twycross, R., Pace, V., Mihalyo, M., \& Wilcock, A. (2013). Acetaminophen (paracetamol). Journal of pain and symptom management, 46(5): 747-755.

Uchadadiya, N., Mehta, F., \& Sanchaniya, P. (2013). HPTLC-densitometric analysis of eperisone hydrochloride and paracetamol in their combined tablet dosage form. Chromatography Research International.

Widagdo, C. T., Naibaho, P., Jayadi, T., \& Danu, S. S. (2016). Pengaruh Pemberian Ekstrak Curcuma Longa Dengan Tingkat Toksisitas Parasetamol Pada Gaster, Hepar Dan Renal Mencit Jantan Galur Swiss. Berkala Ilmiah Kedokteran Duta Wacana, 1(2): 109-119.

Wirastuti, A., Dahlia, A. A., \& Najib, A. (2016). Pemeriksaan kandungan bahan kimia obat (BKO) prednison pada beberapa sediaan jamu rematik. Jurnal Fitofarmaka Indonesia, 3(1): pp. 130-134.

Yamin, M., \& Burhanudin, J. (2018). Pengobatan dan Obat Tradisional Suku Sasak di Lombok. Jurnal Biologi Tropis, 18(1): pp. 1-12.

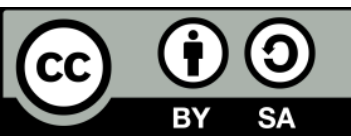

2020 by the authors. Submitted for possible open access publication under the terms and conditions of the Creative Commons Attribution-ShareAlike 4.0 International (CC BY-SA 4.0) license (https://creativecommons.org/licenses/by-sa/4.0/). 